\title{
Multi-period Dynamic Sequential Optimization Model for Prefabricated Affordable Housing Production Scale
}

\author{
CHANG Chunguang $^{\mathrm{a}^{*}}$, LIU Dan ${ }^{\mathrm{b}}$, WU Feifei ${ }^{\mathrm{c}}$ \\ School of Management, Shenyang Jianzhu University, Shenyang 110168, China \\ achang_chunguang@163.com, bcqliudan66@163.com,c2837424831@qq.com
}

\begin{abstract}
Keywords: Prefabricated affordable housing (PAH); Production scale; Mathematical programming Abstract. With the rapid development of living standard, the demand for housing is rising. Prefabricated affordable housing (PAH) is an important way to solve the problem. In this paper, the factors of sequential PAH demand and the future development trend in Shenyang is analyzed by regression equation. By mathematical programming theory, multi-period dynamic sequential optimization model for PAH production scale is established. The minimum difference between demand and supply is the objective function. It gives full consideration of the biggest supply capacity of PAH, the total investment in fixed assets restrictions, government-mandated minimum land area which must be used for PAH. For government departments, the model can provide quantitative decision-making optimization method for multi-period dynamic sequential PAH production scale.
\end{abstract}

\section{Introduction}

With the steady development of economy, housing demand standard is improving. Thereby, affordable housing demand standard for low income urban residents will also change. Currently, prefabricated construction (PC) becomes the main build way with higher speed, excellent quality, less climate condition influence, smaller resource burden, more obvious labor-saving features.

On protection of housing construction decisions, Zhangchen Chen provides new insights for demand forecasting of indemnificatory housing [1]. Ma Jian discusses the scale of investment in the construction of affordable housing [2]. Zhu Jiajie discusses the technology to analyze housing demand and the influencing factors [3]. Wang Xianlei makes deep discussion on how to establish a sustainable public housing supply system [4]. On PC aspect, Qi Baoku and Zhang Yang analyzes the existing bottleneck in the development of PC in view of four aspects [5]. Xu Songlin, Tan Yuang describes the development prospects of industrial technology in the application of PAH [6]. Lv Qing builds an economic estimation system model of fabricated buildings of low energy consumption[7].

\section{Total Sequential Demand Estimating for PAH in Shenyang City}

Usually, there are 3 people in a Chinese urban family, so in design, the mode of PAH should be dominated by two rooms and one hall. According to architectural design of the lowest standard, $45 \mathrm{~m}^{2}$ to $56 \mathrm{~m}^{2}$ of building area is advisable. In this paper, it is on the basis of $56 \mathrm{~m}^{2}$ for related research.

About the average housing area of urban households, the National Bureau of Statistics conducted a large-scale survey research in 2000. Based on current experience, the proportion of housing construction area and actual area is 1.3. Distribution of housing construction area is shown in table 1.

Table 1 Urban Households Housing Construction Area Distribution in Shenyang City in 2000

\begin{tabular}{lcccccc}
\hline Building area $\left(\mathrm{m}^{2}\right)$ & $<26$ & $26-52$ & $52-78$ & $78-104$ & $104-130$ & $>130$ \\
\hline Proportion $(\%)$ & $7.8 \%$ & $32.7 \%$ & $35.5 \%$ & $14.1 \%$ & $5.4 \%$ & $4.5 \%$ \\
\hline
\end{tabular}

Suppose the proportion in the area range is uniformly distributed, then in 2000, family proportion of house area is less than $56 \mathrm{~m}^{2}=7.8 \%+32.7 \%+(56-52) /(78-52) \times 35.5 \%=45.96 \%$. As living standard continues to improve, the proportion of households below $56 \mathrm{~m}^{2}$ will drop. Taking the annual rate of $2 \%$ lower, the proportion is $19.96 \%$ in 2013. According to data Shenyang Municipal Bureau of 
Statistics as shown in table 2, we can use regression equation (1) to predict Shenyang urban households from the year 2014 to 2019, namely, 271.8, 285.5, 300.7, 317.4, 335.6 and 355.2.

$$
y=0.7332 x^{2}-1.6462 x+214.91 \quad R^{2}=0.9262
$$

Table 2 Non-agricultural and Urban Population Between Year 2005 to 2013 in Shenyang City

\begin{tabular}{cccccccccc}
\hline Year & 2005 & 2006 & 2007 & 2008 & 2009 & 2010 & 2011 & 2012 & 2013 \\
\hline $\begin{array}{c}\text { Non-agricultural population } \\
\text { (ten thousand people) }\end{array}$ & 584.5 & 590.5 & 599.7 & 618.8 & 620.5 & 624.7 & 643.2 & 656.8 & 662.3 \\
\hline $\begin{array}{c}\text { The average urban household } \\
\text { population (people) }\end{array}$ & 2.78 & 2.74 & 2.7 & 2.75 & 2.81 & 2.8 & 2.66 & 2.81 & 2.55 \\
\hline $\begin{array}{c}\text { Urban households } \\
\text { Households (million) }\end{array}$ & 210.3 & 215.5 & 222.1 & 225 & 220.8 & 223.1 & 241.8 & 250.8 & 259.7 \\
\hline
\end{tabular}

According to the predicted value of urban households, PAH standard and the proportion of demand, accumulated and new PAH demand can be calculated as shown in Table 3.

Table 3 Cumulative and New PAH Demand from Year 2013 to 2019 (Million m²)

\begin{tabular}{|c|c|c|c|c|c|c|c|}
\hline Year & 2013 & 2014 & 2015 & 2016 & 2017 & 2018 & 2019 \\
\hline & 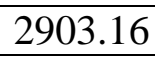 & 3037.71 & & & & & \\
\hline $\mathrm{AH}$ in new housir & & 134.56 & 153.70 & 170.09 & 186.48 & 202.88 & 19.2 \\
\hline
\end{tabular}

\section{Analysis and Forecast to Supply Capacity Constraints of PAH in Shenyang City}

Production-related Constraints Analysis of PAH in Shenyang. Production scale of PAH related constraints includes many factors. As shown in Table 4.

Table 4 Statistics Data in Shenyang City from Year 2005 to 2013

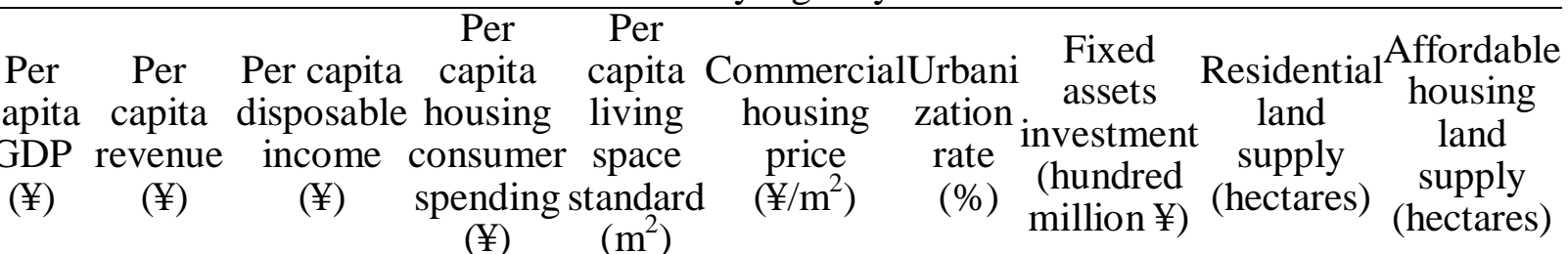

\begin{tabular}{cccccccccc}
\hline$x_{1}$ & $x_{2}$ & $x_{3}$ & $x_{4}$ & $x_{5}$ & $x_{6}$ & $x_{7}$ & $x_{8}$ & $x_{9}$ & $Y$ \\
\hline 201062357 & 7449.24 & 20541.23 & 1364.94 & 30.16 & 5109 & 71.60 & 1004.34 & 1095 & 51 \\
\hline 201172648 & 9641.24 & 23326.20 & 1502.46 & 28.05 & 5614 & 78.50 & 1260.96 & 1303 & 56 \\
\hline 20128048010886.69 & 26430.83 & 1624.09 & 30.50 & 6174 & 78.80 & 1331.43 & 1329 & 71 \\
\hline 20138685012094.21 & 29074.42 & 2378.00 & 31.22 & 6242 & 80.21 & 1574.58 & 1004 & 53 \\
\hline
\end{tabular}

$\mathrm{PAH}$ is different from economic product. It is necessary to build an optimization model to achieve the optimal state. We can calculate the linear correlation coefficient to screen the factors.

As long as the government investment and policy support, the scale of PC component production can meet the requirement of the construction in Shenyang city. From year 2005 to 2013, the influence degree of impact factors to the Shenyang PAH scale by linear correlation coefficient analysis is calculated, and the linear correlation coefficients and the key factors are shown in Table 5.

Table 5 The Linear Correlation Coefficients of each Indicator

\begin{tabular}{cccccccccc}
\hline Indicator & $x_{1}$ & $x_{2}$ & $x_{3}$ & $x_{4}$ & $x_{5}$ & $x_{6}$ & $x_{7}$ & $x_{8}$ & $x_{9}$ \\
\hline Linear correlation coefficient & 0.37 & 0.36 & 0.32 & 0.13 & 0.09 & 0.54 & 0.40 & 0.18 & 0.73 \\
\hline Ranking & 4 & 5 & 6 & 8 & 9 & 2 & 3 & 7 & 1 \\
\hline
\end{tabular}

The Production and Supply Capacity Forecast of PAH in Shenyang. Select four most sensitivity indicators, $x_{9}, x_{6}, x_{7}, x_{1}$, eatablish multiple linear regression model to fit the relationship between PAH and land area. The expression is as follows. Forecast data in Shenyang city (I) is shown in table 6. 


$$
\begin{array}{ll}
\mathrm{y}=-6.13+9.29 \times 10^{-3} x_{9}-2.94 \times 10^{-2} x_{6}-8.06 \times 10^{-6} x_{7}+1.42 \times 10^{-3} x_{1} \\
x_{6}=5103.5 n^{0.1536} & \left(R^{2}=0.9684\right) \\
x_{7}=6.0739 \ln (n)+72.452 & \left(R^{2}=0.8959\right) \\
x_{1}=163.52 n^{2}+5931.1 n+21469 & \left(R^{2}=0.9975\right)
\end{array}
$$

Table 6 Forecast Data in Shenyang City (I)

\begin{tabular}{crrrrrr}
\hline Year & \multicolumn{1}{c}{2014} & \multicolumn{1}{c}{2015} & \multicolumn{1}{c}{2016} & \multicolumn{1}{c}{2017} & \multicolumn{1}{c}{2018} & \multicolumn{1}{c}{2019} \\
\hline$x_{9}(¥)$ & 1079.03 & 1147.26 & 1131.52 & 1117.19 & 1120.50 & 1123.51 \\
\hline$x_{6}\left(¥ / \mathrm{m}^{2}\right)$ & 6534.76 & 6720.35 & 6881.37 & 7023.97 & 7152.20 & 7268.89 \\
\hline$x_{7}(\%)$ & 82.23 & 83.33 & 84.27 & 85.08 & 85.80 & 86.44 \\
\hline$x_{1}(¥)$ & 97132.00 & 106497.02 & 116189.08 & 126208.18 & 136554.32 & 147227.50 \\
\hline
\end{tabular}

Based on the 1.2 multiplied, the largest supply capacity of PAH is shown in Table 7.

Table7 Predictive Value of Construction Scale/Supply Capacity of PAH (Million $\mathrm{m}^{2}$ )

\begin{tabular}{ccccccc}
\hline Year & \multicolumn{1}{c}{2014} & \multicolumn{1}{c}{2015} & 2016 & 2017 & 2018 & 2019 \\
\hline The supply capacity forecast of PAH & 94.18 & 98.64 & 101.70 & 104.80 & 108.22 & 111.68 \\
\hline The largest supply capacity of PAH & 113.02 & 118.37 & 122.04 & 125.76 & 129.86 & 134.02 \\
\hline
\end{tabular}

\section{Multi-period Dynamic Sequential Optimization Model for PAH Production Scale}

Variables Setting. Variables are set as follows.

$x_{j}^{\prime}$ - demand scale of PAH in Shenyang city in year $j$.

$y_{j}$ - maximum supply capacity of PAH in Shenyang city in year $j$.

$x_{j}$ - supply scale of PAH in Shenyang city in year $j$.

$f_{j}$ - unit construction cost of PAH in Shenyang city in year $j$.

$F_{j}$ - fixed assets investment which and be used for PAH in Shenyang city in year $j$.

$r$ - average floor area ratio (FAR) of PAH in Shenyang city. Here, the average value of FAR is 4.

$G_{j}$ - land area which can be used for residential in Shenyang city in year $j$.

$\gamma$ - ratio of PAH construction land to total residential land.

$q_{j}$ - unit market price of PAH in Shenyang city in year $j$.

$c_{j}$ - unit sale price of PAH in Shenyang city in year $j$.

$Q_{j}$ - subsidied capital which can be used on PAH construction in Shenyang city in year $j$.

Model Establishing. On the basis of above variable setting, multi-period dynamic sequential optimization model for PAH production scale is established as follows:

$$
\begin{array}{clc}
\operatorname{MinZ}=\sum_{j=1}^{n}\left|x_{j}{ }^{\prime}-x_{j}\right| & j=1,2, \ldots n \\
\text { s.t. } & x_{j} \leq y_{j} & j=1,2, \ldots n \\
& f_{j} x_{j} \leq F_{j} & j=1,2, \ldots n \\
& x_{j} \geq \gamma G_{j} / r_{j} & j=1,2, \ldots n \\
q_{j} x_{j}-c_{j} x_{j} \leq Q_{j} & j=1,2, \ldots n \\
& x_{j} \geq 0 & j=1,2, \ldots n
\end{array}
$$

The objective function (6) is the demand and supply of construction minimize the difference. Constraint (7) shows the PAH assembly-scale supply of less then maximum supply capacity. Constraint (8) represents the total cost of PAH less than assets investment for the construction. Constraint (9) shows the construction of PAH land area greater than or equal government regulations must be used for construction of affordable housing land area. Constraint (10) represents the 
difference between the market price and the actual selling price of PAH is less than government funding subsidies. Constraint (11) indicates construction scale of PAH supply is greater than zero. Forecast data in Shenyang city (II) is shown in table 8.

Table 8 Forecast Data in Shenyang City (II) (million ¥)

\begin{tabular}{ccccccc}
\hline Year & 2014 & 2015 & 2016 & 2017 & 2018 & 2019 \\
\hline Investment in Fixed Assets & 1528.30 & 1643.81 & 1756.88 & 1867.75 & 1976.62 & 2083.67 \\
\hline Subsidies for the construction of PAH & 504.25 & 443.92 & 396.86 & 348.73 & 298.39 & 248.25 \\
\hline Units Price of PAH $\left(¥ / \mathrm{m}^{2}\right)$ & \multicolumn{5}{c}{3000} \\
\hline
\end{tabular}

By solving above programming model, the optimal solution is as follows: MinZ $=96.48$,

$\left(\mathrm{x}_{1}, \mathrm{x}_{2}, \mathrm{x}_{3}, \mathrm{x}_{4}, \mathrm{x}_{5}, \mathrm{x}_{6}\right)^{\mathrm{T}}=(134.56,153.70,162.72,167.68,173.15,178.69)^{\mathrm{T}}$

Sequential production scale predict data of PAH in Shenyang are as shown in Table 9.

Table 9 The Sequential Production Scale of PAH in Shenyang (Million $\mathrm{m}^{2}$ )

\begin{tabular}{ccccccc}
\hline Year & 2014 & 2015 & 2016 & 2017 & 2018 & 2019 \\
\hline $\begin{array}{c}\text { The time series production scale of } \\
\text { PAH in Shenyang }\end{array}$ & 134.56 & 153.70 & 162.72 & 167.68 & 173.15 & 178.69 \\
\hline
\end{tabular}

\section{Conclusions}

According affordable housing needs and constraints, by establishing production scale multi-stage dynamic sequential optimization model, you can get optimal PAH production scale per year among multi-stage. It benefits for surporting sustainable, healthy and stable development of city PAH. The feasible suggestion obtained by above optimizational model will make PAH and urban to develope in a more scientific way. Thus, it will improve city people's affordable housing utilities.

\section{Acknowledgements}

This work was supported by Humanities and Social Sciences Project from Ministry of Education of the People's Republic of China(15YJA630001); The Natural Science Foundation of Liaoning Province (201502794); Project from Ministry of Housing and Urban-Rural Development of the People's Republic of China(2014-R3-014); Science Research Program of Liaoning Province Education Administration: Liaoning city public safety management by E-CBR (W2014084) \& Research on the industry-university-research-user cooperative innovation mechanism of the market oriented research in Liaoning (W2014085); Work Safety Project of State Administration (2013-13) and Shenyang Scientific and Technological Planning (F14-230-5-19; F15-198-5-15).

\section{References}

[1] Chen Zhangchen, Research on demand forecasting model of urban public housing system, Wuhan: Huazhong University of Science and Technology, 2012(In Chinese).

[2] Jian Ma, Shenyang affordable housing investment and construction scale factors, Liaoning Economic. 5 (2014)56-57(In Chinese).

[3] Jiajie Zhu. Analysis on urban housing demand: method, data and model, City Planning. 38 (2014)143-149(In Chinese).

[4] Xianlei Wang, Study on public housing supply of China, Wuhan: Central China Normal University, 2013(In Chinese).

[5] Baoku Qi, Yang Zhang, Prefabricated construction development bottleneck and countermeasures research, Journal of Shenyang Jianzhu University (Social Science). 17(2015)156-159(In Chinese).

[6] Songlin $\mathrm{Xu}$, Yuang Tan, Vanke industrialized housing technology apply in the affordable housing, Construction Science. 10 (2011) 34-36(In Chinese). 
International Conference on Engineering Management, Engineering Education and Information Technology (EMEEIT 2015)

[7] Qing Lv, Discussion on the economic estimation system model of fabricated building of low energy consumption, Journal of Shenyang Jianzhu University (Social Science). 13(2011)303-306(In Chinese). 